\title{
SOME GENERALIZED INTEGRAL INEQUALITIES AND THEIR APPLICATIONS
}

\author{
LINGLING WAN AND RUN XU
}

Abstract. In this paper, we generalize some integral inequalities to more general situations. These on the one hand generalize and on the other hand furnish a handy tool for the study of qualitative as well as quantitative properties of solutions of integral equations and differential equations. Applications are given to illustrate the usefulness of the inequalities.

Mathematics subject classification (2010): 34B15, 34B18.

Keywords and phrases: Integral inequality, integral equation, differential equation, global existence.

\section{REFERENCES}

[1] L. OU-IANG, The boundedness of solutions of linear differential equations $y^{\prime \prime}+A(t) y=0$, Shuxue Jinzhan 3 (1957), 409-415.

[2] B. G. PACHPATtE, On some new inequalities related to certain inequalities in the theory of differential equations, J. Math. Anal. Appl. 189 (1995), 128-144.

[3] B. G. PaChPatte, On a new inequality suggested by the study of certain epidemic models, J. Math. Anal. Appl. 195 (1995), 638-644.

[4] W. S. Cheung, Some new nonlinear inequalities and applications to boundary value problems, Nonlinear Anal. 64 (2006), 2112-2128.

[5] L. Li, F. Meng, L. He, Some generalized integral inequalities and their applications, J. Math. Anal. Appl. 372 (2010), 339-349.

[6] L. Li, F. Meng, P. Ju, Some new integral inequalities and their applications in studying the stability of nonlinear integro-differential equations with time delay, J. Math. Anal. Appl. 377 (2011), 853-862.

[7] O. Lipovan, Integral inequalities for retarded Volterra equations, J. Math. Anal. Appl. 322 (2006), 349-358.

[8] A. Constantin, Global existence of solutions for perturbed differential equations, Ann. Mat. Pura Appl. 168 (1995), 237-299.

[9] O. Lipovan, A retarded integral inequality and its applications, J. Math. Anal. Appl. 285 (2003), 436-443.

[10] B. G. PAChPATte, On some retarded integral inequalities and applications, J. Inequal. Pure Appl. Math. 3 (2004), Article 18.

[11] B. G. PachPatte, Explicit bounds on certain integral inequalities, J. Math. Anal. Appl. 267 (2002), $48-61$.

[12] O. Lipovan, A retarded Gronwall-like inequality and its applications, J. Math. Anal. Appl. 252 (2000), 389-401.

[13] B. G. PAChPATte, On some new nonlinear retarded integral inequalities, J. Inequal. Pure Appl. Math. 5 (2004), Article 80. 